DOI:10.17951/h.2019.53.1.111-118

\begin{tabular}{lcc}
\hline \multicolumn{1}{c}{ A N N A L E S } \\
UNIVERSITATIS MARIAE CURIE-SKŁODOWSKA \\
LUBLIN - POLONIA \\
VOL. LIII, 1 & SECTIO H \\
\hline
\end{tabular}

\author{
ANDRZEJ SZYMKOWIAK \\ andrzej.szymkowiak@ue.poznan.pl \\ Poznań University of Economics and Business, Department of Commerce and Marketing, \\ al. Niepodległości 10, 61-875 Poznań, Poland \\ ORCID ID: https://orcid.org/0000-0001-5673-7093 \\ URSZULA GARCZAREK-BĄK \\ urszula.garczarek-bak@ue.poznan.pl \\ Poznań University of Economics and Business, Department of Commerce and Marketing, \\ al. Niepodległości 10, 61-875 Poznań, Poland \\ ORCID ID: https://orcid.org/0000-0002-3979-7964
}

\title{
Ambivalent attitudes towards social media
}

Keywords: social media; ambivalence; online users

JEL: D71; A14; D91

How to quote this paper: Szymkowiak, A., \& Garczarek-Bąk, U. (2019). Ambivalent attitudes towards social media. Annales Universitatis Mariae Curie-Skłodowska, sectio H-Oeconomia, Vol. 53, No. 1.

\begin{abstract}
The use of social media (SM) is prevalent not only in private, but also in professional areas, and its overall involvement in our lives has grown immensely over the past decade. According to Bishop (2018), this is a phenomenon unlike anything seen throughout history. Previous studies on SM have analysed this subject unilaterally - giving greater emphasis to the positive or negative impact on its users. This novel article analyses the problem of the co-existence of opposing emotions towards SM based on the example of Facebook. Data from 274 young respondents (since teenagers and young adults spend on average 2-3 hours a day connected to SM sites, more so than other groups) (Healey, 2017), were collected on various areas of SM usage perception. The results present the existence of ambivalent attitudes towards Facebook threefold: as a place for building relationships, as a source of knowledge about the life of friends, and as a source of information. The article raises doubt as to what extent SM has an impact on their users in the future. The
\end{abstract}


issue of SM affecting the user (no matter their age) generally focuses on the negative aspects (SM are being blamed for increasing mental health problems among young people) (Girl Effect team, 2018); therefore, the findings here suggest that a balanced perspective is required, also including some positive aspects.

\section{Introduction}

Nowadays, leading social media (SM), the "love children" of the World Wide Web, boast a high number of user accounts or strong user engagement metrics, since many users integrate the sites into their daily lives and business practices (Borenstein, 2017). For context, as of November 2018, the total worldwide population is 7.6 billion and there are 3.03 billion active SM users (while the Internet has 4.2 billion users). Interestingly, Internet users have an average of 7.6 SM accounts and spend on average 116 minutes a day on social media. The five most famous social network sites worldwide (as of October 2018) ranked by the number of active users (in millions) are: Facebook $(2,234)$, YouTube $(1,900)$, WhatsApp $(1,500)$, Facebook Messenger $(1,300)$ and WeChat $(1,058)$ (Statista, 2018a). The purpose of this article is to reveal the existence of contradictory feelings towards SM, based on the example of Facebook.

Facebook, founded in 2004, is currently the biggest social networking service based on global reach and total active users, which, in the third quarter of 2018 had 2.27 billion monthly active users - logged during the last 30 days (Statista, 2018b) - having on average 155 friends, and $76 \%$ of these check it every day, spending on average 35 minutes. Furthermore, Facebook adds 500,000 new users every day; six new profiles every second. However, there are an estimated 270 million fake Facebook profiles. Curiously enough, half of Internet users who do not use Facebook themselves live with someone who does, so of those, $24 \%$ declare that they look at posts or photos on that person's account. The mean number of friends is 155 . Due to a constant presence in the lives of their users, social networks have a decidedly strong social impact that requires further studies (Smith, 2019).

\section{Literature review}

According to Bik and Goldstein (2013), SM are powerful professional tools for scientists when used appropriately and efficiently. Although SM still carry the stigma of a frivolous time-wasting activity (thus many scientists are reluctant to engage with them) (Rowlands et al., 2011), it is worth noting that over the last few years they have quickly become integrated into many aspects of people's daily lives, and so it is worth elucidating their functions. One must remember that SM sites provide a variety of features that serve different purposes for users. The emergence of Internet-based SM has made it possible for one person to communicate with hundreds or even thousands of other people (Mangold \& Faulds, 2009). One of the main opportunities given to the individuals is to interact without the need for physical meetings (Gruzd et al., 2011). 
Moreover, the core principle of SM is the ability to share content with others (offering easy access to: short status updates, longer text pieces, links, images, audio or video files, publications or CV-related items) (Osterrieder, 2013). Apart from that, SM may be used to seek information about serious topics (Westerman et al., 2014). Generally, SM may be grouped by purpose, including, among others, social networking (such as Facebook, Twitter, etc.), professional networking (LinkedIn), media sharing (YouTube), content production (blogs, microblogs), knowledge/information aggregation (Wikipedia) and virtual reality and gaming environments (Second Life) (Ventola, 2014).

Although the broad definition of social media is constantly evolving, in this article this term refers to Internet-based tools that allow individuals to gather and communicate in real time, including sharing information, ideas, images, messages and other content. A major research question surrounding the use of SM as an information source is how people assess the source credibility of this information (in terms of generated attitudes). As stated by Rowlands et al. (2011), SM have had an enormous impact on many people's personal lives. The ever-increasing amount of information flowing through SM forces the users to compete for attention and influence by relying on other people to spread their message (Romero et al., 2011). Therefore, massive participation in social networks is reflected in the countless number of opinions, news and product reviews posted and discussed constantly. Considering SM as tools which have revolutionized the way people perform communication, it should be noted that there are many advantages and disadvantages of using SM, but it depends on the way in which users utilize them. Apart from general fun and enjoyment options and invaluable promotional tools, SM offer the ability to instantly connect to other people all over the world, find people with common interests, raise self-esteem and increase belongingness - which can indirectly have a positive impact on psychological well-being (Kim, 2016) and lower feelings of loneliness, as well as real-time news and information discovery (Future of working, 2018).

However, apart from these mentioned advantages, using SM may be connected with negative effects, especially in young kids and teenagers (but the same risks may exist in terms of adults, across generations). The American Academy of Pediatrics has paid particular attention to the cyber-bullying and Facebook depression issues (O'Keeffe et al., 2011). Consecutive potential problems relate to feeling overwhelmed by information, privacy issues, social pressure, substitution for offline interaction, distraction and procrastination, and sedentary lifestyle habits and sleep disruption (Moreau, 2018). Furthermore, a careful review of the literature reveals SM studies that concern users' mental well-being, in which the following matters are mainly mentioned: addictiveness, a kind of withdrawal, the triggering of more sadness, greater feelings of isolation, mentally unhealthy comparison factors leading to jealousy (and a vicious cycle), getting caught in the delusion of thinking it will help, and finally, the perception that more friends on SM does not mean the user is more social. Last but not least is the issue of perpetuating false and unreliable information that can cause panic and severe misinformation in society (Walton, 2017). 


\section{Method}

Whereas a number of studies have found a connection between SM use and declines in well-being, some other studies have demonstrated opposite results - namely feelings of being more socially connected as people spend more time on SM. The authors therefore consider that this research field requires more analysis of the concept of ambivalent attitudes declared by SM users, therefore, in this article, the assumption about the ambivalent perception of SM was adopted. According to Cambridge Dictionary (2018), "ambivalence" means being uncertain about how you feel or having two opposing feelings at the same time. In this particular context, based on a literature review, seven areas have been identified for which tests have been carried out. These areas relate to different levels of impact on the lives of users and the resignation of various SM functions: relationship with friends (Relations), knowledge about the life of friends (Life), speed of exchange of opinions (Speed), depth of information about the latest events (Timeliness), modern tools (Novelty), ubiquity of social media (Omnipresence) and source of information obtained (Source). Ambivalence refers to the simultaneous positive and negative attitude towards the object, in this case SM.

In the relationship with friends' area (Relations), hypothesis (H1) assumes that users perceive SM as a way to maintain relationships with friends but also feel less need to maintain personal relationships. In the area of knowledge about the life of friends (Life), hypothesis (H2) assumes that users perceive SM as a good source of knowledge about friends' lives but at the same time believe that content published on SM does not reflect reality or is idealized. In the case of the speed of exchange of opinions area (Speed), hypothesis (H3) assumes that users perceive SM as a quick way to get an opinion but at the same time believe that using SM as a communication tool prolongs the opinion exchange process. In the case of the area of depth of information about the latest events (Timeliness), hypothesis (H4) assumes that users perceive SM as an important source of information about novelties, but at the same time they think that a cursory way of getting familiar with information on SM is not enough. In the case of the modern tool area (Novelty), hypothesis (H5) assumes that users perceive SM as a modern form of contact in a group of friends, but at the same time believe that in a short time there will be better ways to contact a group of friends than the current social networks. In the case of the ubiquity of SM (Omnipresence), hypothesis (H6) assumes that users perceive SM as tools that can be used anywhere in the world, but at the same time believe that the lack of access to these tools leads to irritability. In the case of the source of information obtained (Source), hypothesis (H7) assumes that users perceive SM as an important source of the latest information, but at the same time believe that SM are a source of irrelevant information. In order to test the hypotheses, a questionnaire survey was carried out on a sample of 274 respondents from the so-called millennial generation. This is a group that uses technology and social networking sites like no other and is therefore worthy of detailed research in this area (Au-Yong-Oliveira et al., 2018). The study was conducted on a group of 178 women and 96 men aged $23(\mathrm{SD}=1.9)$ 


\section{Results}

The study was conducted using the CAWI method and the key section consisted of 14 questions on 7 areas. One question for the positive and negative aspect of the above description. Respondents had to respond to the study on a 7-point Likert scale (1 - "strongly disagree", 7 - "strongly agree"). Table 1 presents the basic measures for individual areas, broken down into positive and negative aspects.

Table 1. Descriptive statistics

\begin{tabular}{|l|c|c|c|c|c|}
\hline & Mean & Std.deviation & Variance & Skewness & Kurtosis \\
\hline Relations+ & 4.493 & 1.508 & 2.273 & -0.387 & -0.445 \\
\hline Relations- & 3.456 & 1.769 & 3.128 & 0.219 & -0.888 \\
\hline Life+ & 3.883 & 1.493 & 2.228 & 0.028 & -0.446 \\
\hline Life- & 4.401 & 1.569 & 2.461 & -0.284 & -0.476 \\
\hline Speed+ & 4.493 & 1.404 & 1.972 & -0.189 & -0.389 \\
\hline Speed- & 3.109 & 1.520 & 2.310 & 0.576 & -0.255 \\
\hline Timeliness+ & 4.796 & 1.483 & 2.200 & -0.472 & -0.359 \\
\hline Timeliness- & 3.212 & 1.455 & 2.116 & 0.209 & -0.757 \\
\hline Omnipresence+ & 5.763 & 1.323 & 1.749 & -1.125 & 0.928 \\
\hline Omnipresence- & 3.142 & 1.661 & 2.760 & 0.390 & -0.800 \\
\hline Novelty+ & 5.529 & 1.290 & 1.664 & -0.988 & 1.076 \\
\hline Novelty- & 4.051 & 1.482 & 2.195 & 0.089 & -0.666 \\
\hline Source+ & 5.022 & 1.460 & 2.131 & -0.515 & -0.239 \\
\hline Source- & 4.248 & 1.600 & 2.561 & 0.021 & -0.758 \\
\hline
\end{tabular}

Source: Authors' own study.

In the case of Omnipresence + and Novelty + , it was indicated that the collected data significantly differed from the normal distribution, which limited the possibility of further inference for these plans.
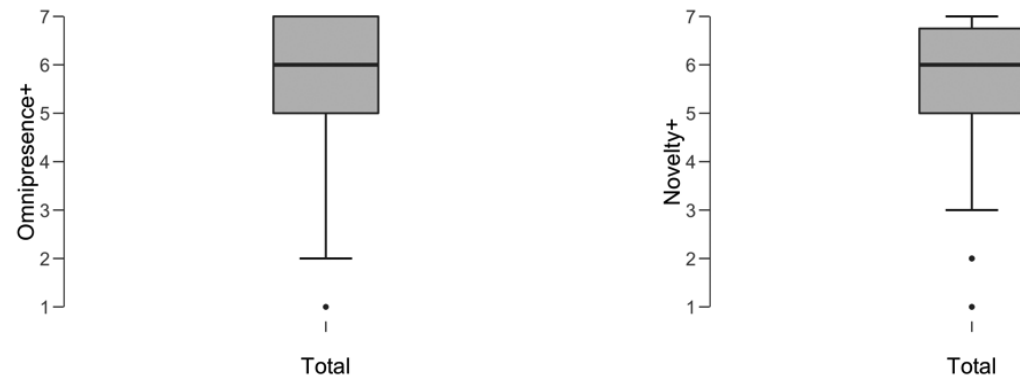

Figure 1. Boxplots of Omnipresence and Novelty

Source: Authors' own study.

At the stage of data analysis, a series of repeated $t$-tests for dependent samples were used. In the conducted research, each difference between means in all the 
other five levels turned out to be statistically significant. The size of the sample also affected this. The study assumes that the basis for adopting the hypothesis about the simultaneous occurrence of equally strong positive and negative attitudes towards SM will be the size of the effect based on the distance between the averages. It is assumed that obtaining a mean or greater effect measured by Cohen's $d$ is the basis for rejecting the ambivalence hypothesis in a given plane, and 0.5 was accepted as the limit value for small effect (Cheng et al., 2018).

Table 2. Paired samples $t$-test

\begin{tabular}{llcccccc}
\hline & & \multirow{2}{*}{$\mathrm{t}$} & $\mathrm{df}$ & $\mathrm{p}$ & $\begin{array}{c}\text { Mean } \\
\text { Difference }\end{array}$ & $\begin{array}{c}\text { SE } \\
\text { Difference }\end{array}$ & Cohen's d \\
\hline Relations + & - Relations- & 8.191 & 273 & $<.001$ & 1.036 & 0.127 & 0.495 \\
Life+ & - Life- & -4.433 & 273 & $<.001$ & -0.518 & 0.117 & -0.268 \\
Speed+ & - Speed- & 11.772 & 273 & $<.001$ & 1.383 & 0.118 & 0.711 \\
Timeliness + & - Timeliness- & 14.388 & 273 & $<.001$ & 1.584 & 0.110 & 0.869 \\
Source+ & - Source- & 6.235 & 273 & $<.001$ & 0.774 & 0.124 & 0.377 \\
Note. Student's $t$-test. & & & & & & \\
\hline
\end{tabular}

Source: Authors' own study.

As a result of the conducted analyses, $\mathrm{H} 3$ and $\mathrm{H} 4$ hypotheses were not confirmed, similar to $\mathrm{H} 5$ and $\mathrm{H} 6$. The findings confirm that there are statistically significant differences between the Relations (H1), Life (H2) and Source (H7) levels, however, the differences are small.

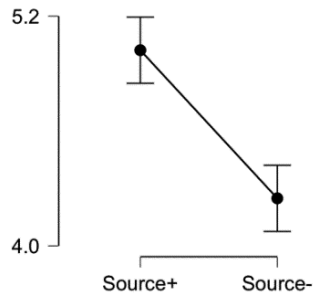

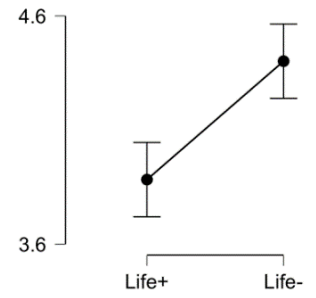

Figure 2. Paired samples $t$-test

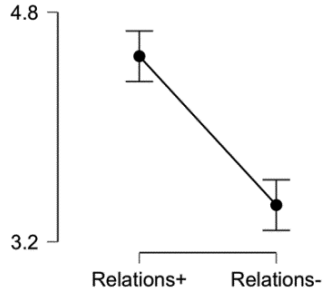

This indicates that SM have a dual nature and simultaneously provoke opposing emotions in the area of shaping and maintaining relationships with loved ones, creating and perceiving the image of the relatives' life and as a source of information. At once fearful and dependent, hopeful and distrustful, attitudes towards SM are perceived as highly ambivalent. 


\section{Conclusions}

SM are increasingly being used as an information source, including both positive and negative features. The current study diagnoses and articulates the ambivalent attitudes declared by millennials. Given that using SM is among the most common activities of today's children and adolescents, who use them for communication and entertainment, studying this routine activity reveals the existence of ambivalent attitudes in terms of maintaining relations, updated life information and source of ir(relevant) information. These data suggest the need for further study of implications for theory and application in positive and negative aspects of SM frequent usage. According to Osterrieder (2013), even though specific platforms will change in the future, the concept of SM is likely to stay, and it is increasingly important to engage with them and become "digitally literate" rather than avoiding or resisting their use at all. In conclusion, it remains unclear whether and to what extent online media communication leads to positive or negative mental and psychological consequences, so this area requires more investigation. Even though the sheer scale of SM usage by young people (particularly on phones) might seem shocking, nowadays it has become simply a different way to process information. Thus, the question should concern the quality and the confidence of SM content.

\section{References}

Au-Yong-Oliveira, M., Gonçalves, R., Martins, J., \& Branco, F. (2018). The social impact of technology on millennials and consequences for higher education and leadership. Telematics and Informatics, 35(4), 954-963. DOI: 10.1016/j.tele.2017.10.007.

Bik, H.M., \& Goldstein, M.C. (2013). An introduction to social media for scientists. PLoS Biol, 11(4), e1001535. DOI: 10.1371/journal.pbio.1001535.

Bishop, L. (2018). The true purpose of social media 2018. Retrieved from: https://umidigital.co.uk/blog/ true-purpose-of-social-media-2018/ [access: 18.05.2019].

Borenstein, A. (2017). Building a brand with enterprise social media - a look at AO.com. Retrieved from: https://smbp.uwaterloo.ca/2017/04/building-a-brand-with-enterprise-social-media-a-look-at-ao-com/ [access: 18.05.2019].

Cambridge Dictionary (2018). Meaning of “ambivalent” in the English Dictionary. Retrieved from: https:// dictionary.cambridge.org/dictionary/english/ambivalent [access: 18.05.2019].

Cheng, X., Fu, S., \& de Vreede, G.-J. (2018). A mixed method investigation of sharing economy driven car-hailing services: Online and offline perspectives. International Journal of Information Management, 41, 57-64. DOI: https://doi.org/10.1016/j.ijinfomgt.2018.03.005.

Future of working (2018). 10 advantages and disadvantages of social networking. Retrieved from: https:// futureofworking.com/10-advantages-and-disadvantages-of-social-networking/ [access: 18.05.2019].

Girl Effect team (2018). How social media affects young people. Retrieved from: https://www.girleffect. org/stories/how-social-media-affects-young-people/ [access: 18.05.2019].

Gruzd, A., Tiryakian, E.A., Wellman, B., \& Takhteyev, Y. (2011). Imagining Twitter as an Imagined community. American Behavioral Scientist, 55(10), 1294-1318. DOI: 10.1177/0002764211409378.

Healey, J. (2017). Social Media and Young People. Vol. 415. Thirroul, N.S.W.: The Spinney Press. 
Kim, H.H.-s. (2016). The impact of online social networkicfng on adolescent psychological well-being (WB): a population-level analysis of Korean school-aged children. International Journal of Adolescence and Youth, 22(3), 364-376. DOI: 10.1080/02673843.2016.1197135.

Mangold, W.G., \& Faulds, D.J. (2009). Social media: The new hybrid element of the promotion mix. Business Horizons, 52(4), 357-365. DOI: 10.1016/j.bushor.2009.03.002.

Moreau, E. (2018). The pros and cons of social networking. A look at the ups and downs of being so digitally connected to people. Retrieved from: https://www.lifewire.com/advantages-and-disadvantages-of-social-networking-3486020 [access: 18.05.2019].

O'Keeffe, G.S., Clarke-Pearson, K., Council on Communications, \& Media. (2011). The impact of social media on children, adolescents, and families. Pediatrics, 127(4), 800-804. DOI: 10.1542/peds.2011-0054.

Osterrieder, A. (2013). The value and use of social media as communication tool in the plant sciences. Plant Methods, 9(26).

Romero, D.M., Galuba, W., Asur, S., \& Huberman, B.A. (2011). Influence and passivity in social media. Machine Learning and Knowledge Discovery in Databases. Lecture Notes in Computer Science, 6913.

Rowlands, I., Nicholas, D., Russell, B., Canty, N., \& Watkinson, A. (2011). Social media use in the research workflow. Learned Publishing, 24(3), 183-195. DOI: 10.1087/20110306.

Smith, K. (2019). 121 amazing social media statistics and facts. Retrieved from: https://www.brandwatch. $\mathrm{com} / \mathrm{blog} /$ amazing-social-media-statistics-and-facts/ [access: 18.05.2019].

Statista (2018a). Most famous social network sites worldwide as of October 2018, ranked by number of active users (in millions). Retrieved from: https://www.statista.com/statistics/272014/global-socialnetworks-ranked-by-number-of-users/ [access: 18.05.2019].

Statista (2018b). Number of monthly active Facebook users worldwide as of 3rd quarter 2018 (in millions). Retrieved from: https://www.statista.com/statistics/264810/number-of-monthly-active-facebook-users-worldwide/ [access: 18.05.2019].

Ventola, C.L. (2014). Social media and health care professionals: benefits, risks, and best practices. Pharmacy \& Therapeutics, 39(7).

Walton, A.G. (2017). 6 ways social media affects our mental health. Retrieved from: https://www.forbes. com/sites/alicegwalton/2017/06/30/a-run-down-of-social-medias-effects-on-our-mental-health/\#d9c166c2e5af [access: 18.05.2019].

Westerman, D., Spence, P.R., \& Van Der Heide, B. (2014). Social Media as Information Source: Recency of Updates and Credibility of Information. Journal of Computer-Mediated Communication, 19(2), 171-183. DOI: 10.1111/jcc4.12041. 